\title{
Desempenho agronômico de genótipos de capim-braquiária em sucessão à soja
}

\author{
Luís Armando Zago Machado(1) e Cacilda Borges do Valle(2)
} ${ }^{(1)}$ Embrapa Agropecuária Oeste, Caixa Postal 661, CEP 79804-970 Dourados, MS. E-mail: zago@cpao.embrapa.br (2)Embrapa Gado de Corte,
Caixa Postal 154, CEP 79002-970 Campo Grande, MS. E-mail: cacilda@cnpgc.embrapa.br

Resumo - O objetivo deste trabalho foi avaliar o desempenho agronômico de genótipos de capim-braquiária [Urochloa brizantha (Syn. Brachiaria brizantha)] em sucessão à soja, para uso em sistemas de integração lavoura-pecuária. Os genótipos Marandu, MG 4, Xaraés, Piatã, Arapoty e B 6, foram avaliados na safrinha, durante a estação seca, e a soja na safra de verão, em esquema de sucessão, de 2007 a 2010. Em cada ano, as forrageiras foram semeadas em março, avaliadas em cortes sucessivos até o final de setembro e dessecadas em outubro para a realização do plantio direto da soja em novembro. Utilizou-se o delineamento de blocos ao acaso, com quatro repetições. Xaraés e B 6 estiveram entre os genótipos com maior produção de forragem. A cultivar Xaraés apresentou menores teores de proteína bruta, digestibilidade in vitro da matéria orgânica, cálcio e fósforo, embora esses teores possam ser considerados bons para o gênero, uma vez que o solo de cultivo apresentava boa fertilidade. Há variação entre os genótipos de $U$. brizantha quanto ao desempenho na safrinha. A cultivar Xaraés e o genótipo B 6 destacam-se para compor sistemas de produção integrados com lavoura. Os genótipos MG 4 e B6 são facilmente dessecados com o herbicida glifosato. A produtividade de grãos de soja não é significativamente afetada pelo cultivo em sucessão aos genótipos de $U$. brizantha.

Termos para indexação: Brachiaria brizantha, Urochloa brizantha, Glycine max, forrageira, integração lavourapecuária, safrinha.

\section{Agronomic performance of palisade grass genotypes in succession to soybean}

\begin{abstract}
The objective of this work was to evaluate the agronomic performance of palisade grass genotypes [Urochloa brizantha (Syn. Brachiaria brizantha)] in succession to soybean, for use on crop-livestock integration systems. The Marandu, MG 4, Xaraés, Piatã, Arapoty e B 6 genotypes were evaluated as a second crop, during the dry season, and soybean, in the summer crop, in a succession scheme, from 2007 to 2010. In each year, forages were sown in March and evaluated at successive cuts until late September, then desiccated in October to allow for no-tillage soybean seeding in november. A randomized complete block design with four replicates was used. Xaraés and B 6 genotypes were among those with higher forage production. The Xaraés cultivar showed lower contents of crude protein, in vitro digestibility of organic matter, calcium, and phosphorus, which, however, can be considered good for this genus, since it was grown in fertile soil. There is variation among U. brizantha genotypes as to their performance in the second crop. The Xaraés and B 6 genotypes show better performance in succession to soybean, in integrated production systems. The MG 4 and B 6 genotypes are easily desiccated with glyphosate herbicide. Soybean yield is not significantly affected by the cultivation in succession to the $U$. brizantha genotypes.
\end{abstract}

Index terms: Brachiaria brizantha, Urochloa brizantha, Glycine max, forage, crop-livestock integration, second crop.

\section{Introdução}

A desagregação do solo e a crescente incidência de pragas, doenças e plantas daninhas estão entre as principais dificuldades da atividade agrícola. $\mathrm{Na}$ bovinocultura de corte e leite, a degradação de pastagens têm resultado na morte do pasto em extensas áreas, nas regiões Centro-Oeste e Norte do Brasil (Valle et al., 2000).
A integração lavoura-pecuária é uma alternativa à produção de grãos e à pecuária em sistemas especializados. A integração dessas atividades resulta em melhorias para os atributos físicos do solo e favorecem o controle de plantas daninhas, nematoides e doenças (Asmus, 2005; Marchão et al., 2007; Toledo-Souza et al., 2008; Pacheco et al., 2009).

Na região Centro-Oeste, predominam as pastagens do gênero Urochloa (Syn. Brachiaria), principalmente 
de $U$. brizantha cv. Marandu que, embora seja bem adaptada, apresenta grande estacionalidade na produção de forragem (Costa et al., 2005). Em condições de pastejo, há demanda por forragem durante todo o ano. A redução na disponibilidade de forragem no período da seca, portanto, torna necessária a suplementação do rebanho para que não haja grandes perdas na produtividade animal (Barioni et al., 2003). Dessa forma, a utilização de sistemas integrados de lavoura e pecuária é uma alternativa para minimizar os efeitos da estacionalidade da produção de forragem, já que possibilitam o aumento da área de pastagem, durante a estação seca, com forrageiras temporárias. O cultivo de forrageiras anuais, tais como aveia, milheto e sorgo, ou de perenes, dos gêneros Urochloa e Panicum, na entressafra das culturas de verão, pode suprir parcial ou totalmente a demanda dos animais (Pacheco et al., 2008; Machado \& Assis, 2010).

Há um grande número de artigos que abordam o uso de forrageiras anuais para sucessão às culturas de verão; porém, poucos tratam de espécies de Urochloa e Panicum com essa finalidade. Em curtos períodos de avaliação, a produção de matéria seca das forrageiras perenes é inferior à das anuais, pois elas demoram mais tempo para se estabelecer (Muraishi et al., 2005). Em intervalos mais longos, espécies de Urochloa apresentaram maior produção de matéria seca do que milheto e sorgo, e foram mais eficientes na supressão de plantas daninhas, o que resultou em maior rendimento de grãos de soja em sucessão (Pacheco et al., 2008, 2009).

Entre os genótipos de $U$. brizantha, ocorrem variações fenológicas quanto às proporções de folha e colmo e quanto à qualidade nutricional da forragem que, em condição de pastejo, resultam em diferentes níveis de produtividade animal (Silveira, 2006; Flores et al., 2008; Euclides et al., 2008, 2009; Machado \& Assis, 2010; Silveira et al., 2010).

Machado \& Assis (2010) e Ferreira et al. (2010) identificaram $U$. brizantha como uma das espécies mais adequadas para a produção de forragem e palha; porém, a eficiência de controle dessa forrageira com herbicida glifosato é normalmente baixa. Além disso, as plantas dessa espécie demoram a entrar em senescência e somente proporcionam condição ideal para o plantio das culturas de sucessão, de 21 a 28 dias após a aplicação do herbicida, o que contribui para o atraso da semeadura. Como as cultivares de $U$. brizantha disponíveis no mercado foram pouco avaliadas em estudos comparativos, e existem linhagens em fase final de lançamento (Valle et al., 2004), é necessário conhecer os genótipos disponíveis, para inseri-los nos sistemas de integração lavoura-pecuária.

O objetivo deste trabalho foi avaliar o desempenho agronômico de genótipos de $U$. brizantha, cultivados em sucessão à soja, para uso em sistemas de integração lavoura-pecuária.

\section{Material e Métodos}

O experimento foi realizado na Embrapa Agropecuária Oeste, em Dourados, MS, a $22^{\circ} 14$ 'S e $54^{\circ} 49^{\prime} \mathrm{W}$, a $408 \mathrm{~m}$ de altitude, e em Latossolo Vermelho distroférrico. A área experimental já estava sendo utilizada por aproximadamente três décadas com culturas anuais, principalmente soja, e apresentava as seguintes características químicas antes da implantação do experimento: $\mathrm{pH}$ em água, 6,$0 ; \mathrm{pH}$ em $\mathrm{CaCl}_{2}, 5,3$; conteúdos de $\mathrm{Al}^{3}, \mathrm{Ca}^{2+}, \mathrm{Mg}^{2+}, \mathrm{H}+\mathrm{Al}$ e K${ }^{+}$de $0 ; 6,7 ; 2,8$; 5,8 e $0,58 \mathrm{cmol}_{\mathrm{c}} \mathrm{dm}^{-3}$, respectivamente; $\mathrm{P}$ (Mehlich 1), 25,2 $\mathrm{mg} \mathrm{dm}^{-3}$; CTC efetiva, $10,1 \mathrm{cmol}_{\mathrm{c}} \mathrm{dm}^{-3} ; \mathrm{V}, 63 \%$; e $\mathrm{MO}, 32,7 \mathrm{~g} \mathrm{~kg}^{-1}$.

Utilizou-se o delineamento experimental de blocos ao acaso, com seis tratamentos e quatro repetições. Foram avaliadas as cultivares Marandu, MG 4, Xaraés, Piatã, Arapoty, de U. brizantha, além da linhagem B 6, da mesma espécie. Durante três anos, foi avaliado o desempenho das forrageiras na estação seca, e o da soja, em sucessão a esses tratamentos, na chuvosa. As parcelas mediram $3,2 \times 5,0 \mathrm{~m}$ e foram constituídas por oito linhas da forrageira, espaçadas em 0,40 $\mathrm{m}$, sucedidas por sete linhas de soja, espaçadas em $0,45 \mathrm{~m}$.

A semeadura dos experimentos com as forrageiras foi realizada em plantio direto, em sucessão à soja, sempre na segunda quinzena de março, já que, em Mato Grosso do Sul, o milho é a principal cultura na estação seca. Assim, as forrageiras são normalmente plantadas após a época de semeadura do milho, recomendada pelo zoneamento agroclimático, para até 10 de março. As forrageiras foram semeadas em 19/3/2007, 25/3/2008 e 26/3/2009, sem adubação. A disponibilidade hídrica foi variável, ao longo do experimento, e ocorreu deficit no estabelecimento das forrageiras, em todos os anos de avaliação. Em 2009, esse deficit foi mais pronunciado, pois não foi registrada precipitação pluvial no mês de abril (Figura 1). 
As forrageiras foram avaliadas em regime de cortes sucessivos, quando as plantas atingiam, em média, $50 \mathrm{~cm}$ de altura, até o final do mês de setembro. As amostragens foram realizadas com o corte das plantas a $20 \mathrm{~cm}$ acima do solo, nas quatro linhas centrais de cada parcela, tendo-se deixado duas linhas de bordadura de cada lado e $1 \mathrm{~m}$ no início e no final da parcela. As amostragens para determinação da produção de forragem foram realizadas em: 19/7/2007 e $2 / 10 / 2007 ; 27 / 6 / 2008,18 / 8 / 2008,29 / 9 / 2008$; 29/7/2009, 14/9/2009 e 5/10/2009.

Após a pesagem da amostra verde de forragem, retirou-se uma subamostra de aproximadamente $400 \mathrm{~g}$, para a determinação das frações de folha e colmo, e o restante da amostra foi devolvido para a respectiva parcela. As subamostras foram colocadas em estufa com ventilação forçada, a $61^{\circ} \mathrm{C}$, por 72 horas e, posteriormente, pesadas para a determinação da massa de matéria seca.

Os teores de proteína bruta (PB) e a digestibilidade in vitro da matéria orgânica (DIVMO) foram determinados, em todas as amostras de lâminas foliares, por espectroscopia de reflectância do infravermelho próximo (NIRS). Foram utilizadas curvas de calibração avaliadas por meio de padrões. Essas determinações foram realizadas em laboratório da Embrapa Gado de Corte, em Campo Grande, MS. Os teores de Ca e P foram determinados no Laboratório de Solos, da Embrapa Agropecuária Oeste, em Dourados, MS.

Após a última avaliação da produção de forragem, realizada no final de setembro, ocorreu a rebrotação, e as plantas foram dessecadas uma semana após a primeira chuva do mês de outubro, com $1.080 \mathrm{~g} \mathrm{ha}^{-1}$ do i.a. de glifosato (equivalente ácido de $\mathrm{N}$-fosfonometil glicina), além de $1 \mathrm{~L} \mathrm{ha}^{-1}$ de óleo mineral e $2 \mathrm{~kg} \mathrm{ha}^{-1} \mathrm{de}$ sulfato de amônio como adjuvantes. Após 21 dias da aplicação do herbicida, foram realizadas as avaliações visuais da eficiência de controle das forrageiras, que consistiu na atribuição de notas em escala de zero (todos os perfilhos vivos) a 100 (todos perfilhos mortos), por um avaliador treinado.

Nos três anos de avaliação, antes da semeadura da soja, foram aplicados mais $720 \mathrm{~g} \mathrm{ha}^{-1}$ do i.a. de glifosato a toda a área experimental, para o controle de plantas remanescentes da primeira dessecação. A semeadura mecânica da soja, em plantio direto sobre a palha das forrageiras, foi realizada em 20/11/2007, $12 / 11 / 2008$ e 14/11/2009, com $300 \mathrm{~kg} \mathrm{ha}^{-1}$ (4-18-8), $220 \mathrm{~kg} \mathrm{ha}^{-1}(5-25-15)$ e $200 \mathrm{~kg} \mathrm{ha}^{-1}(10-20-10)$ da fórmula $\mathrm{N}-\mathrm{P}_{2} \mathrm{O}_{5}-\mathrm{K}_{2} \mathrm{O}$ de adubo, respectivamente. Utilizou-se a cultivar de soja BRS 256 RR, em 2007, e a 245 RR, em 2008 e 2009. As sementes de soja foram tratadas com fungicida à base de carboxina $\mathrm{e}$ thiram, e, posteriormente, receberam inoculação com Bradyrhizobium japonicum em veículo turfoso.

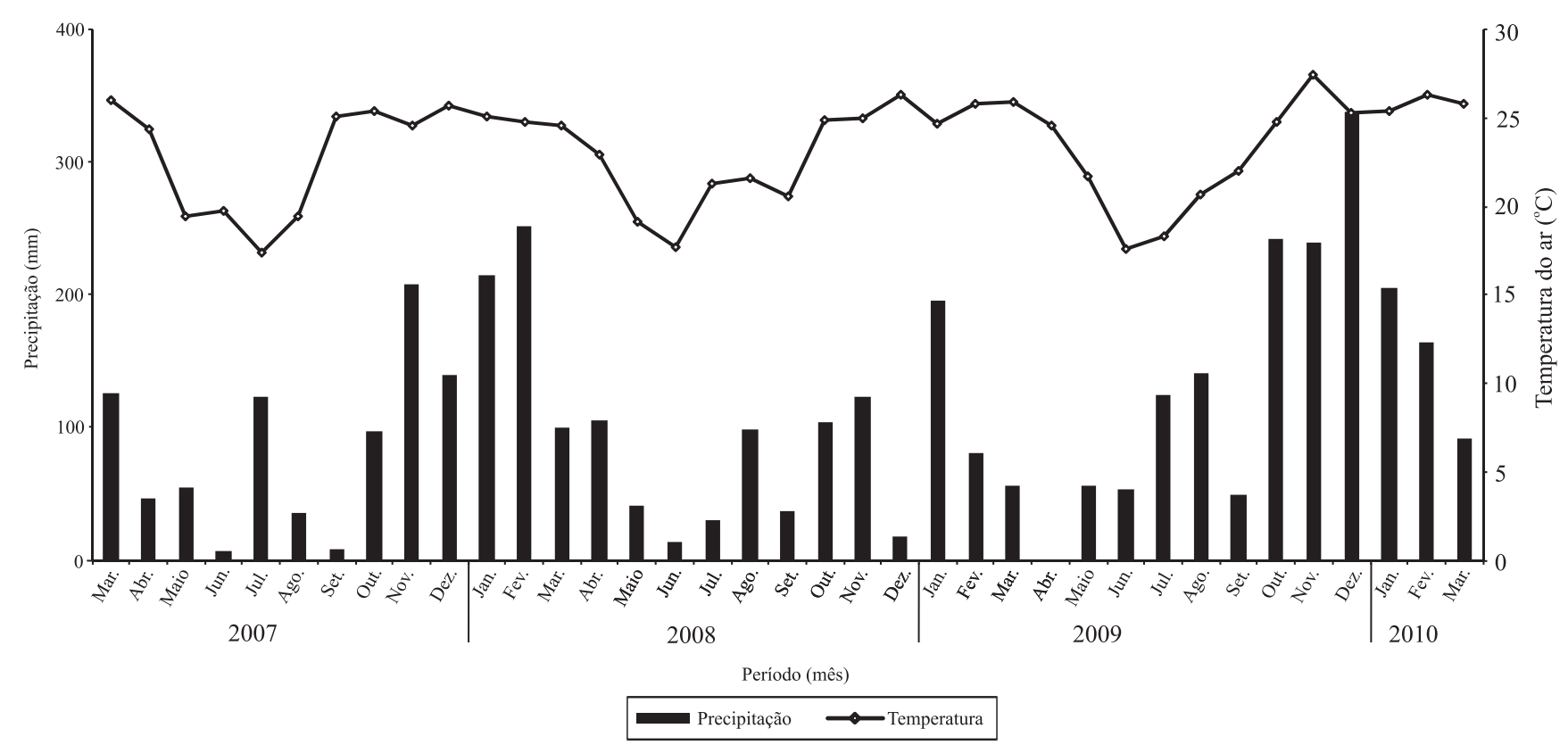

Figura 1. Precipitação pluvial e temperatura média mensal do ar, em Dourados, MS, de março de 2007 a março de 2010. 
A colheita da soja foi realizada com colheitadeira de parcelas, em seis linhas de $3 \mathrm{~m}$ de comprimento, no centro da parcela. Posteriormente, foi determinado o teor de umidade dos grãos.

Os resultados foram submetidos à análise de variância, e as médias foram comparadas pelo teste de Tukey, a 5\% de probabilidade, com auxílio do programa Assistat 7.4 Beta (Silva \& Azevedo, 2006).

\section{Resultados e Discussão}

Em 2007, a cultivar MG 4 produziu $4.984 \mathrm{~kg} \mathrm{ha}^{-1}$ de matéria seca de forragem e foi superior à Piatã e à Arapoty, mas não diferiu da Marandu e da Xaraés, nem da linhagem B 6 (Tabela 1). Em 2008, a linhagem $\mathrm{B} 6$ foi superior às cultivares $\left(5.299 \mathrm{~kg} \mathrm{ha}^{-1}\right)$, mas não diferiu de 'Xaraés'. Em 2009, tanto B 6 como 'Xaraés' foram superiores às demais, com 6.116 e $6.189 \mathrm{~kg} \mathrm{ha}^{-1}$, respectivamente, mas não diferiram de 'MG 4' e 'Piatã'. Em avaliações realizadas com oito forrageiras, durante

Tabela 1. Produção de matéria seca de forragem, lâminas foliares e colmos e relação folha/colmo de seis genótipos de Urochloa brizantha, de 2007 a $2009^{(1)}$.

\begin{tabular}{|c|c|c|c|c|}
\hline \multirow[t]{2}{*}{ Genótipo } & \multicolumn{3}{|c|}{ Produção $\left(\mathrm{kg} \mathrm{ha}^{-1}\right)$} & \multirow[t]{2}{*}{ Folha/colmo } \\
\hline & Forragem & Folha & Colmo & \\
\hline & \multicolumn{4}{|c|}{ Ano 2007} \\
\hline Marandu & $4.724 \mathrm{ab}$ & $3.233 \mathrm{ab}$ & $1.491 \mathrm{abc}$ & $2,25 b$ \\
\hline MG 4 & $4.964 a$ & $3.069 \mathrm{ab}$ & $1.895 \mathrm{a}$ & $1,62 b$ \\
\hline Xaraés & $4.571 \mathrm{ab}$ & $3.627 \mathrm{a}$ & $943 c$ & $4,0 \mathrm{a}$ \\
\hline Piatã & $3.695 b c$ & $2.681 \mathrm{bc}$ & $1.014 \mathrm{c}$ & $2,7 b$ \\
\hline Arapoty & $3.150 \mathrm{c}$ & $1.923 \mathrm{c}$ & $1.226 \mathrm{bc}$ & $1,6 b$ \\
\hline B 6 & $4.541 \mathrm{ab}$ & $2.805 \mathrm{~b}$ & $1.735 \mathrm{ab}$ & $1,6 \mathrm{~b}$ \\
\hline \multirow[t]{2}{*}{ CV $(\%)$} & 12,7 & 12,3 & 18,0 & 20,6 \\
\hline & \multicolumn{4}{|c|}{ Ano 2008} \\
\hline Marandu & $3.728 b c$ & $2.867 \mathrm{c}$ & $861 \mathrm{~b}$ & $3,3 b$ \\
\hline MG 4 & $3.079 \mathrm{c}$ & $2.287 \mathrm{c}$ & $792 b$ & $2,9 b$ \\
\hline Xaraés & $3.849 \mathrm{ab}$ & $4.115 \mathrm{a}$ & $735 b$ & $5,6 \mathrm{a}$ \\
\hline Piatã & $4.008 \mathrm{bc}$ & $3.043 \mathrm{bc}$ & $965 b$ & $3,2 b$ \\
\hline Arapoty & $2.795 \mathrm{c}$ & $2.083 \mathrm{c}$ & $712 b$ & $3,0 \mathrm{~b}$ \\
\hline B 6 & $5.299 \mathrm{a}$ & $3.851 \mathrm{ab}$ & $1.448 \mathrm{a}$ & $2,7 \mathrm{~b}$ \\
\hline \multirow[t]{2}{*}{ CV (\%) } & 14,1 & 13,8 & 17,6 & 9,6 \\
\hline & \multicolumn{4}{|c|}{ Ano 2009} \\
\hline Marandu & $4.145 b$ & $3.520 \mathrm{~b}$ & $626 b c$ & $6,0 \mathrm{a}$ \\
\hline MG 4 & $5.265 \mathrm{ab}$ & $4.098 \mathrm{ab}$ & $1.167 \mathrm{ab}$ & $3,6 \mathrm{ab}$ \\
\hline Xaraés & $6.189 \mathrm{a}$ & $5.229 \mathrm{a}$ & $961 b$ & $5,7 \mathrm{a}$ \\
\hline Piatã & $5.432 \mathrm{ab}$ & $4.456 \mathrm{ab}$ & $977 b$ & $4,6 a b$ \\
\hline Arapoty & $1.044 \mathrm{c}$ & $806 c$ & $238 \mathrm{c}$ & $3,9 \mathrm{ab}$ \\
\hline B 6 & $6.116 a$ & $4.564 \mathrm{ab}$ & $1.551 \mathrm{a}$ & $3,0 \mathrm{~b}$ \\
\hline $\mathrm{CV}(\%)$ & 12,2 & 11,7 & 22,0 & 20,1 \\
\hline
\end{tabular}

${ }^{(1)}$ Médias seguidas de letras iguais, nas colunas, não diferem entre si, pelo teste Tukey, a 5\% de probabilidade. Em 2007 e 2008, n=4; em 2009, n=3. a estação seca, Machado \& Assis (2010) observaram que 'Xaraés' foi uma das mais produtivas, tanto submetida a cortes sucessivos quanto em crescimento livre, e superou 'Marandu'. Tendência semelhante foi observada por Lupinati (2010), com as mesmas cultivares, e por Costa et al. (2009) que avaliaram 'Marandu', 'Xaraés' e 'MG 4'. Em avaliação realizada durante a estação seca, com sistema de irrigação, Cruz (2010) obteve maior produção de forragem com 'Xaraés', em comparação a 'Piatã' e 'Marandu', muito superior à observada no presente trabalho, em razão de o experimento ter sido conduzido sob irrigação.

Ao avaliar diferentes genótipos de U. brizantha, na fase de estabelecimento (soma de três cortes), Valle et al. (2004) obtiveram maior rendimento de matéria seca com a linhagem B 6, em comparação às cultivares Marandu e Piatã, mas que não diferiu de Xaraés e Arapoty. Provavelmente, a maior produção de forragem da cultivar Xaraés está relacionada a seu ciclo reprodutivo, pois o período em que essa cultivar se mantém na fase vegetativa é duas vezes maior do que o de Piatã, Marandu e Arapoty (Silveira, 2006).

Hare et al. (2009) obtiveram maior produção de forragem com a cultivar Toledo, em comparação a outras cinco, inclusive 'Marandu', em avaliações realizadas nas estações das águas e da seca. Na avaliação das cultivares Xaraés, Marandu e Piatã, Euclides et al. (2008) obtiveram maior produção de forragem com a primeira, nas estações das águas e da seca. Como reflexo da maior produção de forragem, Euclides et al. (2009) observaram que a cultivar Xaraés suporta maior taxa de lotação, o que resulta em maior ganho de peso vivo por hectare, em comparação à Piatã e Marandu.

Ao avaliar várias forrageiras em crescimento livre e por um período mais longo, que foi do início de março ao final de novembro, Ferreira et al. (2010) concluíram que a produção de fitomassa das cultivares de $U$. brizantha foi semelhante, embora a Marandu tenha produzido $2.000 \mathrm{~kg} \mathrm{ha}^{-1}$ de matéria seca a mais do que a Xaraés. Nem sempre a produção de forragem submetida a cortes e a produção de matéria seca em crescimento livre seguem a mesma tendência (Machado \& Assis, 2010).

A produção de lâminas foliares de 'Xaraés' foi superior à das demais cultivares, embora com resultados semelhantes à de 'Marandu' e 'MG 4', em 2007, de B 6, em 2008, e à de 'MG 4', 'Piatã' e B 6, em 2009 
(Tabela 1). Os resultados estão de acordo com Machado \& Assis (2010), que observaram que a cultivar Xaraés está entre as forrageiras que apresentaram a maior produção de lâminas foliares, com $2.162 \mathrm{a} 3.090 \mathrm{~kg} \mathrm{ha}^{-1}$. Esses resultados são um pouco inferiores aos obtidos no presente trabalho, provavelmente, em razão das condições ambientais distintas, já que a metodologia empregada foi a mesma.

A produção de colmos de 'MG 4', em 2007, foi superior à das demais cultivares, embora não tenha diferido de 'Marandu' e de B 6. Em 2008 e 2009, o tratamento com a linhagem B 6 foi superior aos demais tratamentos, embora no último ano não se tenha observado diferença significativa em relação à cultivar MG 4.

Quanto à relação folha/colmo, 'Xaraés' foi superior às demais, em 2007 e 2008, com valores de 4,0 a 5,6. Em 2009, as cultivares Xaraés e Marandu foram superiores apenas à linhagem $\mathrm{B} 6$. O fato de a cultivar Xaraés manter-se por mais tempo na fase vegetativa (Silveira, 2006) ajuda a explicar a menor relação folha/colmo e uma das mais baixas produções de colmos obtidas com este genótipo. Silveira et al. (2010) observaram que 'Xaraés' apresenta algumas características interessantes como planta forrageira, em comparação a 'Piatã' e 'Marandu', como maior taxa de elongação de folhas, menor taxa de elongação de colmos e maior comprimento das folhas.

Os valores obtidos com a relação folha/colmo foram bem superiores aos obtidos por Euclides et al. (2008), provavelmente em razão da metodologia empregada, pois, enquanto os autores citados avaliaram pastagens por três anos, no presente trabalho, as pastagens foram avaliadas apenas durante a estação seca, com plantas estabelecidas no mesmo ano e, portanto, jovens.

Embora tenha apresentado grande produção de forragem e de folhas, a linhagem B 6 foi uma das que apresentaram a menor relação folha/colmo, em razão do acúmulo de colmos. Segundo Carvalho (1997), a fração colmo pode constituir uma limitação física à ingestão de matéria seca, pois, dos componentes da forragem, a fração folha é a que apresenta melhor qualidade e, de acordo com Forbes \& Hodgson (1985), pode representar mais de $80 \%$ da dieta dos bovinos. Todavia, os colmos são de grande valor para a cobertura do solo nos sistemas de integração lavoura-pecuária, já que resíduos vegetais, com alta relação $\mathrm{C} / \mathrm{N}$ e elevado teor de lignina, apresentam menores taxas de decomposição (Sainju et al., 2007).
O teor de proteína bruta das lâminas foliares de 'Marandu' foi superior aos de 'Xaraés', 'Arapoty' e 'B 6', mas não diferiu de 'MG 4' e 'Piatã', em 2007 (Tabela 2). Em 2008, as cultivares MG 4 e Arapoty apresentaram teores superiores aos da Xaraés e não diferiram das demais. Em 2009, a cultivar Arapoty apresentou teores superiores aos da Xaraés e não diferiu das demais cultivares.

O comportamento entre as cultivares variou entre os anos avaliados, o que dificultou a identificação dos genótipos com maior teor de proteína bruta. A causa provável foi a baixa variação genética entre as cultivares, todas da mesma espécie. Em todos os anos, porém, 'Xaraés' apresentou teor de proteína bruta inferior ao de alguns dos genótipos avaliados. Enquanto 'Xaraés' esteve entre as mais produtivas (Tabela 1) e com mais baixo teor de proteína bruta, 'Arapoty' foi a menos produtiva, com teores de proteína bruta superiores em dois anos de avaliação (2008 e 2009).

Tabela 2. Teores de proteína bruta (PB), digestibilidade in vitro da matéria orgânica (DIVMO), e de Ca e P de lâminas foliares de seis genótipos de Urochloa brizantha, avaliados de 2007 a $2009^{(1)}$.

\begin{tabular}{|c|c|c|c|c|}
\hline \multirow[t]{2}{*}{ Genótipo } & PB & DIVMO & $\mathrm{Ca}$ & $\mathrm{P}$ \\
\hline & \multicolumn{2}{|c|}{----------- $(\%)$----------- } & \multicolumn{2}{|c|}{-------- $\left(\mathrm{g} \mathrm{kg}^{-1}\right)$-------- } \\
\hline & \multicolumn{4}{|c|}{ Ano 2007} \\
\hline Marandu & $13,3 \mathrm{a}$ & $75,3 \mathrm{a}$ & $4,67 \mathrm{a}$ & $1,10 \mathrm{a}$ \\
\hline MG 4 & $12,5 \mathrm{abc}$ & $74,9 \mathrm{ab}$ & $4,18 \mathrm{ab}$ & $1,00 \mathrm{ab}$ \\
\hline Xaraés & $11,8 \mathrm{c}$ & $65,5 \mathrm{~d}$ & $4,33 \mathrm{ab}$ & $0,85 b$ \\
\hline Piatã & $12,9 \mathrm{ab}$ & $70,3 \mathrm{c}$ & $3,65 b$ & $0,80 \mathrm{~b}$ \\
\hline Arapoty & $11,9 \mathrm{bc}$ & $74,2 \mathrm{abc}$ & $4,00 \mathrm{ab}$ & $0,88 \mathrm{ab}$ \\
\hline B 6 & $11,9 \mathrm{bc}$ & $70,5 b c$ & $4,18 \mathrm{ab}$ & $0,98 \mathrm{ab}$ \\
\hline \multirow[t]{2}{*}{ CV (\%) } & 3,9 & 2,8 & 7,4 & 10,7 \\
\hline & \multicolumn{4}{|c|}{ Ano 2008} \\
\hline Marandu & $15,5 \mathrm{ab}$ & $73,5 \mathrm{bc}$ & $4,60 \mathrm{a}$ & $2,05 \mathrm{bc}$ \\
\hline MG 4 & $16,1 \mathrm{a}$ & $77,7 \mathrm{ab}$ & $4,70 \mathrm{a}$ & $2,32 \mathrm{a}$ \\
\hline Xaraés & $14,3 b$ & $67,6 \mathrm{~d}$ & $4,45 \mathrm{a}$ & $2,00 \mathrm{c}$ \\
\hline Piatã & $14,9 \mathrm{ab}$ & $70,4 \mathrm{~cd}$ & $3,95 b$ & $1,70 \mathrm{~d}$ \\
\hline Arapoty & $16,0 \mathrm{a}$ & $78,0 \mathrm{a}$ & $4,28 \mathrm{ab}$ & $2,23 \mathrm{ab}$ \\
\hline B 6 & $15,3 \mathrm{ab}$ & $74,7 \mathrm{abc}$ & $4,48 \mathrm{a}$ & $2,15 \mathrm{abc}$ \\
\hline \multirow[t]{2}{*}{$\mathrm{CV}(\%)$} & 4,6 & 2,5 & 4,3 & 4,5 \\
\hline & \multicolumn{4}{|c|}{ Ano 2009} \\
\hline Marandu & $14,4 \mathrm{ab}$ & $74,9 \mathrm{bc}$ & $4,73 a$ & $1,93 \mathrm{ab}$ \\
\hline MG 4 & $14,6 a b$ & $74,0 \mathrm{bc}$ & $4,90 \mathrm{a}$ & $2,13 a$ \\
\hline Xaraés & $13,1 b$ & $67,8 \mathrm{c}$ & $4,40 \mathrm{a}$ & $1,70 \mathrm{ab}$ \\
\hline Piatã & $14,1 \mathrm{ab}$ & $71,6 \mathrm{bc}$ & $4,30 \mathrm{a}$ & $1,70 \mathrm{ab}$ \\
\hline Arapoty & $16,6 \mathrm{a}$ & $83,7 \mathrm{a}$ & $4,53 \mathrm{a}$ & $1,60 \mathrm{~b}$ \\
\hline B 6 & $15,5 \mathrm{ab}$ & $77,3 \mathrm{ab}$ & $4,53 a$ & $2,13 \mathrm{a}$ \\
\hline CV (\%) & 6,3 & 3,6 & 6,3 & 8,2 \\
\hline
\end{tabular}


A digestibilidade in vitro da matéria orgânica da cultivar Marandu foi de 75,3\%, em 2007, tendo sido superior às demais e não diferido de 'MG 4' e 'Arapoty' (Tabela 2). Em 2008 e 2009, o comportamento das cultivares em relação a esta variável foi semelhante ao teor de proteína bruta, sendo que a cultivar Arapoty apresentou teores de 78,0 e 83,7\%, respectivamente.

Machado \& Assis (2010) também obtiveram, com a cultivar Xaraés, teores de PB de 12,6 e 12,7\%, e Divmo de 63,1 e 64,2\%, em lâminas foliares, valores inferiores aos observados pelos autores para 'Marandu' e para $U$. ruziziensis e $U$. decumbens. Os resultados do presente trabalho estão de acordo com os de Lupinati (2010), em que a cultivar Marandu apresentou maior teor de PB e Divmo na forragem, em relação a Xaraés, durante as estações de inverno e primavera.

A maior Divmo obtida com lâminas foliares de 'Marandu', em relação a 'Xaraés' e 'Piatã', está de acordo com Euclides et al. (2009), porém diferem em magnitude. Costa et al. (2005) avaliaram pastagem de 'Marandu', numa condição de pasto permanente, e seus resultados diferem do presente trabalho, mas estão de acordo com os dos autores acima. Provavelmente, a diferença entre os resultados deve-se à metodologia empregada; enquanto no presente trabalho as forrageiras, avaliadas sob corte durante a estação seca, eram plantas jovens e estabelecidas em sucessão à soja, com boa fertilidade de solo, Costa et al. (2005) e Euclides et al. (2009) avaliaram essas cultivares durante a estação das águas e seca, sob pastejo, durante três anos. Resultados discordantes do presente trabalho também foram obtidos por Costa et al. (2009), em que a cultivar Xaraés apresentou maior teor de PB que a Marandu e a MG 4. Essas diferenças também poderiam ser atribuídas à metodologia empregada, já que os autores citados avaliaram os genótipos em condições controladas, em casa de vegetação, e o corte das amostras foi feito a $5 \mathrm{~cm}$ acima do nível do solo, a intervalos fixos de 30 dias. A maior Divmo de 'Marandu', em comparação a 'Xaraés', também foi observada por Flores et al. (2008) em alguns períodos.

O teor de Ca de 'Marandu' foi superior ao de 'Arapoty', em 2007, e ao de 'Piatã', em 2008, mas não diferiu do teor de $\mathrm{Ca}$ dos demais genótipos. Em 2009, a diferença no teor de $\mathrm{Ca}$ foi semelhante entre os genótipos e variou de 4,30 a 4,73 $\mathrm{g} \mathrm{kg}^{-1}$. Esses resultados são semelhantes aos obtidos por Batista \& Monteiro (2010), para a cultivar Marandu.
O teor de P de 'Marandu' foi superior ao de 'Xaraés' e 'Piatã', em 2007, e não diferiu do dos demais genótipos. Em 2008, 'MG 4' foi superior a 'Marandu', 'Xaraés' e 'Piatã', mas não diferiu das demais quanto a esse caráter. Em 2009, 'MG 4' e B 6 apresentaram teores de P superiores aos de 'Arapoty'; porém, não diferiram dos de 'Marandu', 'Xaraés' e 'Piatã'. Os teores de P encontrados no presente trabalho foram semelhantes aos obtidos por Euclides et al. (2009), para 'Marandu', 'Xaraés' e 'Piatã', mas inferiores aos observados por Cecato et al. (2004), para 'Marandu'. A diferença dos resultados pode estar relacionada à metodologia empregada, pois, no estudo de Euclides et al. (2009) e no presente trabalho, o teor de $\mathrm{P}$ foi avaliado nas lâminas foliares, enquanto Cecato et al. (2004) determinaram-no na matéria seca total.

A produtividade de grãos de soja foi semelhante nas sucessões aos diferentes genótipos de $U$. brizantha, embora tenham ocorrido diferenças de 284 a $413 \mathrm{~kg} \mathrm{ha}^{-1}$ entre os tratamentos (Tabela 3). Esse fato

Tabela 3. Eficiência de controle das plantas pela dessecação com glifosato e produtividade de grãos de soja, cultivada em sucessão a genótipos de Urochloa brizantha, de 2007 a $2009^{(1)}$

\begin{tabular}{lcc}
\hline Genótipo & $\begin{array}{c}\text { Eficiência de controle } \\
(\%)\end{array}$ & $\begin{array}{c}\text { Produtividade de grãos } \\
\left(\mathrm{kg} \mathrm{ha}^{-1}\right)\end{array}$ \\
\hline & \multicolumn{2}{c}{ Ano 2007 } \\
Marandu & $84,5 \mathrm{ab}$ & $2.718 \mathrm{a}$ \\
MG 4 & $95,8 \mathrm{a}$ & $2.460 \mathrm{a}$ \\
Xaraés & $76,3 \mathrm{c}$ & $2.472 \mathrm{a}$ \\
Piatã & $88,8 \mathrm{ab}$ & $2.474 \mathrm{a}$ \\
Arapoty & $89,0 \mathrm{ab}$ & $2.534 \mathrm{a}$ \\
B 6 & $94,7 \mathrm{a}$ & $2.305 \mathrm{a}$ \\
\hline CV (\%) & 4,6 & 8,9 \\
\hline & & \\
Marandu & $68,3 \mathrm{a}$ & $2.400 \mathrm{a}$ \\
MG 4 & $60,2 \mathrm{a}$ & $2.271 \mathrm{a}$ \\
Xaraés & $24,2 \mathrm{~b}$ & $2.275 \mathrm{a}$ \\
Piatã & $48,7 \mathrm{a}$ & $2.277 \mathrm{a}$ \\
Arapoty & $63,0 \mathrm{a}$ & $2.289 \mathrm{a}$ \\
B 6 & $71,3 \mathrm{a}$ & $2.116 \mathrm{a}$ \\
\hline CV (\%) & 15,1 & 7,6 \\
\hline & & \\
Marandu & Ano 2009 & $2.040 \mathrm{a}$ \\
MG 4 & $76,5 \mathrm{~cd}$ & $2.217 \mathrm{a}$ \\
Xaraés & $93,5 \mathrm{a}$ & $2.153 \mathrm{a}$ \\
Piatã & $68,8 \mathrm{~d}$ & $2.147 \mathrm{a}$ \\
Arapoty & $80,3 \mathrm{bc}$ & $1.938 \mathrm{a}$ \\
B 6 & $90,3 \mathrm{ab}$ & $2.231 \mathrm{a}$ \\
\hline CV (\%) & $96,0 \mathrm{a}$ & 15,1 \\
\hline
\end{tabular}

${ }^{(1)}$ Médias seguidas de letras iguais na coluna não diferem entre si pelo teste Tukey, a $5 \%$ de probabilidade. Em 2007 e 2008, n=4; em 2009, n=3. 
pode estar relacionado à pequena variação imposta pelas forrageiras ao meio, já que são todas de uma única espécie. Resultados semelhantes foram obtidos por Machado \& Assis (2010), que não observaram diferenças na produtividade de grãos da soja semeada em sucessão a diferentes espécies forrageiras. Ao avaliar soja em sucessão à forrageiras e plantas de cobertura, Carvalho et al. (2004) e Muraishi et al. (2005) também não observaram diferença quanto à produtividade de grãos da soja.

Pacheco et al. (2009) obtiveram resultados semelhantes de produtividade de grãos de soja cultivada em sucessão a forrageiras e plantas de cobertura; porém, a fitomassa deixada por essas culturas teve grande efeito na supressão de plantas daninhas. Ferreira et al. (2010) constataram diferenças no rendimento de algodão em caroço e em pluma, quando semeado em sucessão a 15 forrageiras e plantas para cobertura do solo. Porém, entre as cultivares Marandu, MG 4, Xaraés e Piatã, os autores obtiveram rendimentos semelhantes para essas variáveis.

A eficiência de controle do glifosato, na dessecação das forrageiras, variou de acordo com o ano (Tabela 3 ). Em 2007, a eficiência de controle dos genótipos MG 4 e B6 foi superior à de Xaraés, mas não diferiu da eficiência dos demais tratamentos. Em 2008, todos os genótipos foram superiores a 'Xaraés'. Em 2009, os genótipos MG 4 e B 6 foram superiores aos demais, embora não tenham diferido de 'Arapoty'. Os resultados obtidos em 2008 podem estar relacionados à baixa precipitação pluvial, ocorrida após a aplicação do herbicida (Figura 1), o que dificultou a translocação do herbicida nas plantas, em razão do estresse hídrico. Resultados semelhantes foram obtidos por Ferreira et al. (2010), em cujo estudo as cultivares Piatã, MG4 e Marandu não diferiram entre si, quanto à eficiência de controle, mas foram superiores a 'Xaraés'. Machado \& Assis (2010) também obtiveram eficiência de controle semelhante para 'Marandu' e 'Xaraés', comparadas a outras forrageiras, semelhantemente ao que ocorreu em 2009 no presente estudo.

Nos três anos de avaliação, a linhagem B 6, além de ter figurado entre as mais produtivas (Tabela 1), foi um dos que apresentou a mais alta eficiência de controle na dessecação, de 71 a 96 \% (Tabela 3). Essa característica é importante, pois após as forrageiras receberem a aplicação do herbicida, são necessários de 30 a 40 dias para a realização da semeadura da soja (Tecnologias de produção da soja - Região Central do Brasil 2011, 2010). Além dessa característica, as forrageiras para a integração lavoura-pecuária devem estabelecer-se com menor disponibilidade hídrica e produzir durante a estação seca, já que são formadas em sucessão às culturas de verão e, na medida do possível, devem contribuir para o controle de pragas, doenças e plantas daninhas. Além disso, essas forrageiras devem cobrir adequadamente o solo, para a realização de plantio direto, e o preço das sementes deve ser compatível com o propósito, já que estão sendo utilizadas como uma espécie anual. Nos sistemas de integração lavoura-pecuária, forrageiras mais produtivas durante a estação seca são importantes porque contribuem para a diminuição da estacionalidade da produção das pastagens de $U$. brizantha, conforme resultados obtidos por Costa et al. (2005).

\section{Conclusões}

1. O potencial de produção de forragem na entressafra, em sucessão à soja, varia entre os genótipos de Urochloa brizantha avaliados, com destaque para a cultivar Xaraés e para a linhagem B 6.

3. Os genótipos MG 4 e B 6 são mais suscetíveis à dessecação com o herbicida glifosato.

4. A produtividade de grãos de soja não é significativamente afetada pelo cultivo em sucessão aos genótipos de $U$. brizantha .

\section{Agradecimentos}

Ao Conselho Nacional de Desenvolvimento Científico e Tecnológico, por bolsa concedida.

\section{Referências}

ASMUS, G.L. Reação de algumas culturas de cobertura utilizadas no sistema plantio direto ao nematóide reniforme. Dourados: Embrapa Agropecuária Oeste, 2005. 4p. (Embrapa Agropecuária Oeste. Comunicado técnico, 99).

BARIONI, L.G.; MARTHA JUNIOR, G.B.; RAMOS, A.K.B.; VELOSO, R.F.; RODRIGUES, D. de C.; VILELA, L. Planejamento e gestão do uso de recursos forrageiros na produção de bovinos em pastejo. In: SIMPÓSIO SOBRE MANEJO DA PASTAGEM, 20. 2003, Piracicaba. Produção animal em pastagens: situação atual e perspectivas: anais. Piracicaba: FEALQ, 2003. p.105-154.

BATISTA, K.; MONTEIRO, F.A. Variações nos teores de potássio, cálcio e magnésio em capim-marandu adubado com doses de nitrogênio e de enxofre. Revista Brasileira de Ciência do Solo, v.34, p.151-161, 2010. 
CARVALHO, M.A.C. de; ATHAYDE, M.L.F.; SORATTO, R.P.; ALVES, M.C.; ARF, O. Soja em sucessão a adubos verdes no sistema plantio direto e convencional em solo de Cerrado. Pesquisa Agropecuária Brasileira, v.39, p.1141-1148, 2004.

CARVALHO, P.C. de F. A estrutura da pastagem e o comportamento ingestivo de ruminantes em pastejo. In: SIMPÓSIO SOBRE AVALIAÇÃO DE PASTAGENS COM ANIMAIS, 2., 1997, Maringá. Anais. Maringá: Universidade Estadual de Maringá, 1997. p.25-52.

CECATO, U.; PEREIRA, L.A.F.; JOBIM, C.C.; MARTINS, E.N.; BRANCO, A.F.; GALBEIRO, S.; MACHADO, A.O. Influência das adubações nitrogenada e fosfatada sobre a composição químico-bromatológica do capim-marandu (Brachiaria brizantha (Hochst) Stapf cv. Marandu. Acta Scientiarum. Animal Sciences, v.26, p.409-416, 2004.

COSTA, K.A. de P.; OLIVEIRA, I.P. de; FAQUIN, V.; SILVA, G.P.; SEVERIANO, E. da C. Produção de massa seca e nutrição nitrogenada de cultivares de Brachiaria brizantha (A. Rich.) Stapf sob doses de nitrogênio. Ciência e Agrotecnologia, v.33, p.1578-1585, 2009.

COSTA, K.A. de P.; ROSA, B.; OLIVEIRA, I.P. de; CUSTÓDIO, D.P.; SILVA, D.C. e Efeito da estacionalidade na produção de matéria seca e composição bromatológica da Brachiaria brizantha cv. Marandu. Ciência Animal Brasileira, v.6, p.187-193, 2005.

CRUZ, P.G. da. Produção de forragem em Brachiaria brizantha: adaptação geração e avaliação de modelos empíricos e mecanicistas para estimativa do acúmulo de forragem. 2010. 102p. Tese (Doutorado) - Escola Superior de Agricultura Luiz de Queiroz, Piracicaba.

EUCLIDES, V.P.B.; MACEDO, M.C.M.; VALLE, C.B. do; BARBOSA, R.A.; GONÇALVES, W.V. Produção de forragem e características da estrutura do dossel de cultivares de Brachiaria brizantha sob pastejo. Pesquisa Agropecuária Brasileira, v.43, p.1805-1812, 2008.

EUCLIDES, V.P.B.; MACEDO, M.C.M.; VALLE, C.B. do; DIFANTE, G. dos S.; BARBOSA, R.A.; CACERE, E.R. Valor nutritivo da forragem e produção animal em pastagens de Brachiaria brizantha. Pesquisa Agropecuária Brasileira, v.44, p.98-106, 2009.

FERREIRA, A.C. de B.; LAMAS, F.M.; CARVALHO, M. da C.S.; SALTON, J.C.; SUASSUNA, N.D. Produção de biomassa por cultivos de cobertura do solo e produtividade do algodoeiro em plantio direto. Pesquisa Agropecuária Brasileira, v.45, p.546-553, 2010.

FLORES, R.S.; EUCLIDES, V.P.B.;ABRÃO, M.P.C.; GALBEIRO, S.; DIFANTE, G. dos S.; BARBOSA, R.A. Desempenho animal, produção de forragem e características estruturais dos capins marandu e xaraés submetidos a intensidades de pastejo. Revista Brasileira de Zootecnia, v.37, p.1355-1365, 2008.

FORBES, T.D.A.; HODGSON, J. Comparative studies of the influence of sward conditions on the ingestive behaviour of cows and sheep. Grass and Forage Science, v.40, p.69-77, 1985.

HARE, M.D.; TATSAPONG, P.; PHENGPHET, S. Herbage yield and quality of Brachiaria cultivars, Paspalum atratum and
Panicum maximum in North-East Thailand. Tropical Grasslands, v.43, p.65-72, 2009.

LUPINATI, G.C. Produção, características morfológicas e valor nutritivo de cultivares de Brachiaria brizantha submetidas a duas alturas de resíduo. 2010. 64p. Tese (Doutorado) Universidade Estadual Paulista, Botucatu.

MACHADO, L.A.Z.; ASSIS, P.G.G. de. Produção de palha e forragem por espécies anuais e perenes em sucessão à soja. Pesquisa Agropecuária Brasileira, v.45, p.415-422, 2010.

MARCHÃO, R.L.; BALBINO, L.C.; SILVA, E.M. da; SANTOS JUNIOR, J. de D.G. dos; SÁ, M.A.C. de; VILELA, L.; BECQUER, T. Qualidade física de um Latossolo Vermelho sob sistemas de integração lavoura-pecuária no Cerrado. Pesquisa Agropecuária Brasileira, v.42, p.873-882, 2007.

MURAISHI, C.T.; LEAL, A.J.F.; LAZARINI, E.; RODRIGUES, L.R.; GOMES JUNIOR, F.G. Manejo de espécies vegetais de cobertura do solo e produtividade do milho e da soja em semeadura direta. Acta Scientiarum. Agronomy, v.27, p.199-206, 2005.

PACHECO, L.P.; PIRES, F.R.; MONTEIRO, F.P.; PROCÓPIO, S. de O.; ASSIS, R.L. de; CARMO, M.L. do.; PETTER, F.A. Desempenho de plantas de cobertura em sobressemeadura na cultura da soja. Pesquisa Agropecuária Brasileira, v.43, p.815-823, 2008.

PACHECO, L.P.; PIRES, F.R.; MONTEIRO, F.P.; PROCÓPIO, S. de O.; ASSIS, R.L.; CARGNELUTTI FILHO, A.; CARMO, M.L. do; PETTER, F.A. Sobressemeadura da soja como técnica para supressão da emergência de plantas daninhas. Planta Daninha, v.27, p.455-463, 2009

SAINJU,U.M.;SCHOMBERG,H.H.;SINGH,B.P.;WHITEHEAD, W.F.; TILLMAN, P.G.; LACHNICHTWEYERS, S.L. Cover crop effect on soil carbon fractions under conservation tillage cotton. Soil and Tillage Research, v.96, p.205-218, 2007.

SILVA, F. de A.S. e.; AZEVEDO, C.A.V. de. A new version of the Assistat-Statistical assistance software. In: WORLD CONGRESS ON COMPUTERS IN AGRICUlTURE, 4., Orlando. Anais. Orlando: American Society of agricultural and Biological Engineers, 2006. p.393-396.

SILVEIRA, M.C.T. da. Caracterização morfogênica de oito cultivares do gênero Brachiaria e dois do gênero Panicum. 2006. 91p. Dissertação (Mestrado) - Universidade Federal de Viçosa, Viçosa.

SILVEIRA, M.C.T. da; NASCIMENTO JÚNIOR, D. do; SILVA, S.C. da; EUCLIDES, V.P.; MONTAGNER, D.B.; SBRISSIA, A.F.; RODRIGUES, C.S.; SOUSA, B.M. de L.; PENA, K. da S.; VILELA, H.H. Morphogenetic and structural comparative characterization of tropical forage grass cultivars under free growth. Scientia Agricola, v.67, p.136-142, 2010.

TECNOLOGIAS de produção da soja - Região Central do Brasil 2011. Londrina: Embrapa Soja, 2010. 255p. (Embrapa Soja. Sistemas de produção, 14).

TOLEDO-SOUZA, E.D. de; SILVEIRA, P.M. da; LOBO JUNIOR, M.; CAFÉ FILHO, S.C. Sistemas de cultivo, sucessões de culturas, 
densidade do solo e sobrevivência de patógenos de solo. Pesquisa Agropecuária Brasileira, v.43, p.971-978, 2008.

VALLE, C.B. do; EUCLIDES, V.P.B.; PEREIRA, J.M.; VALÉRIO, J.R.; PAGLIARINI, M.S.; MACEDO, M.C.M.; LEITE, G.G.; LOURENÇO, A.J.; FERNANDES, C.D.; DIAS FILHO, M.B.; LEMPP, B.; POTT, A.; SOUZA, M.A. de. O capim-xaraés (Brachiaria brizantha cv. Xaraés) na diversificação das pastagens de braquiária. Campo Grande: Embrapa Gado de Corte, 2004. 36p. (Embrapa Gado de Corte. Documentos, 149).

VALLE, L. da C.S.; VALÉRIO, J.R.; SOUZA, O.C. da; FERNANDES, C.D.; CORREAA, E.S. Diagnóstico de morte de pastagens nas regiões leste e nordeste do Estado de Mato Grosso. Campo Grande: Embrapa Gado de Corte, 2000. (Embrapa Gado de Corte. Documentos, 97).

Recebido em 8 de abril de 2011 e aprovado em 10 de outubro de 2011 